\title{
The counterimmunoelectrophoretic detecting of serum response to Rhizopus oryzae and Candida albicans in diabetic and non-diabetic subjects
}

\author{
Ali Mikaeili' and Isaac Karimi ${ }^{*}$ \\ *Correspondence: isaac_karimi2000@yahoo.com

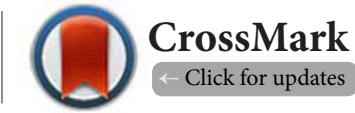

'Department of Medical Mycology, School of Medicine, Kermanshah University of Medical Sciences, Kermanshah, Iran. ${ }^{2}$ Laboratory of Molecular and Cellular Biology, Department of Basic Veterinary Sciences, School of Veterinary Medicine, Razi University, Kermanshah, Iran.

\begin{abstract}
Background: Increased susceptibility to invasive fungal diseases is one of the most important issues in diabetic patients. The purpose of the present study was to assess immunologic status of diabetic and non-diabetic subjects regarding to the subclinical infections with Rhizopus oryzae and Candida albicans.

Methods: The classic counterimmunoelecterophoresis (CIEP) assay has been employed to detect serum response to $R$. oryzae and C. albicans in diabetic $(\mathrm{n}=100$; mean fasting blood sugar 170 \pm 102$)$ and non-diabetic $(\mathrm{n}=100$; mean fasting blood sugar $90 \pm 12)$ subjects.

$\underline{\text { Results: }}$ The anti-R. oryzae and anti-C. albicans antibodies have been detected in diabetic subjects more than those of non-diabetic subjects $(\mathrm{p}<0.001)$. The relative risk of candidiasis and mucormycosis in diabetic subjects were 2.8 and 19.0 times more than nodiabetic subjects, respectively. Absolute risk increase was 0.27 (2700 per 10,000 people) for candidiasis compared to 0.18 (1800 per 10,000 people) for mucormycosis in diabetes mellitus (DM). The number needed to treat for the prevention of candidiasis and mucormycosis in DM was 3.7 (370 per 10,000 people) and 5.5 (550 per 10,000 people), respectively.

Conclusion: CIEP would be considered as the first tool to screen latent mucormycosis and candidiasis in DM, however its characteristics like sensitivity and specificity should be measured in comparison to a gold standard technique.
\end{abstract}

Keywords: Candidiasis, mucormycosis, diabetes mellitus, counterimmunoelecterophoresis

\section{Background}

Both clinical and experimental studies evidently showed that (mutual) relationship is between diabetes mellitus (DM) and opportunistic fungal diseases like zygomycosis (mucormycosis) and candidiasis [1]. In this context, zygomycosis is a group of severe angio-invasive infections caused by the zygomycetes like Rhizopus oryzae [2]. Although the most advantageous management of zygomycosis has not been defined, rapid diagnosis, identification and mitigation of risk factors, chemotherapy, surgical debridement where needed, and the use of adjunctive therapies all contribute to control this life-threatening disease [3]. The accelerated immunosenescence that occurred in DM and especially in poorly managed DM or in DM with ketoacidosis has been the most commonly recognized underlying cause associated with different clinical aspects of zygomycosis e.g., [2,4].

Candidiasis is another invasive fungal infection that is a frequent cause of morbidity and mortality in immunosuppresed patients like diabetic subjects and organ transplant recipients
[5]. Various clinical features of candidiasis caused by different species mainly Candida glabrata and Candida albicans that have been detected in diabetic subjects [6].

The main issue associated with an improved survival of diabetic or immunosuppressive patients that susceptible to invasive fungal diseases (IFDs) is a quick satisfactory antifungal therapy. In order to be able to arrange a successful chemotherapeutic program, a prompt diagnosis is mandatory. However, conventional mycological methods lack sensitivity and take several days from sampling to a positive outcome $[7,8]$. Therefore, other rapid methods are recommended to manage patients who are at risk of IFDs. However, these advanced methods usually employed for patients that showed some kinds of clinical signs [9]. It is noteworthy to launch a strategic plan for campaigning IFDs that may occur in immunocomplicated situation like DM. In this sense, rapid and reliable diagnostic tools like immunodiagnostic tests seem to be rational especially in preventive programme of public health.

According to a huge body of literature that states high 
Mikaeili et al. Research Journal of Infectious Diseases 2014,

probability of occurrence of IFDs in DM [10], the present study was aimed to find the apparent immunologic status of diabetic and non-diabetic subjects in Iran regarding to the subclinical infections with Rhizopus oryzae and Candida albicans as two major pathogens involved in IFDs.

\section{Methods}

\section{Study subjects}

The Medical Ethical Committee of the Medical University of Kermanshah, Iran reviewed and approved this study. The study group comprised a total of 200 adults (100 diabetic patients and 100 healthy subjects) attending to the Kermanshah University of Medical Education Mycology Laboratory in Kermanshah province, west Iran $\left(34^{\circ} 18^{\prime} \mathrm{N}, 47^{\circ} 3^{\prime} \mathrm{E}\right.$ and $1420 \mathrm{~m}$ above sea level). The including criteria for diabetic patients were according to World Health Organization as a fasting plasma glucose concentration $>126 \mathrm{mg} / \mathrm{dl}$. The including criteria for non-diabetic subjects were lack of history of diabetic symptoms like polyuria, polydipsia and unexplained weight loss and a fasting plasma glucose concentration $<126 \mathrm{mg} /$ dl. The individuals included in the present study received no antibiotic treatment, immunosuppressive agents, corticosteroid therapy, X-ray exposure or radiotherapy. In addition individuals that suffered from leukemia and AIDS have been excluded from study.

\section{Counterimmunoelecterophoresis (CIEP) assay}

The sera were immediately harvested and stored at $-70^{\circ} \mathrm{C}$. CIEP was carried out on $8 \times 10 \mathrm{~cm}^{2}$ glass plates covered with type II agarose gel (Sigma-Aldrich, St Louis, MO) diluted in Veronal buffer solution, $\mathrm{pH}$ 8.2. Two parallel rows of wells $(n=8)$ punched in the gel respectively received our laboratory-manufactured antigens of Rhizopus oryzae and Candida albicans (10 $\mu$ l for each; methodology not shown), normal saline solution (10 $\mu$;; namely negative control) and immunized goat antiserum (10ul; namely positive control).

The slides were subjected to a $5 \mathrm{mAmp}$ electric current for 120 min and then immersed in Veronal buffer solution, $\mathrm{pH}$ 8.2 for $24 \mathrm{~h}$. After finishing electrophoresis, the slides were immersed in sodium nitrate for $10 \mathrm{~min}$ followed by immersion in saline solution (2\%) for $24 \mathrm{~h}$, then to make them dry, a piece of paper containing distilled water was laid on them and they were incubated in $40^{\circ} \mathrm{C}$ degree for $48 \mathrm{~h}$. After drying, the gel was stained with Coomassie brilliant blue (Sigma-Aldrich, St Louis, MO). The existence of precipitate bands was considered as positive reaction.

\section{Statistical analysis}

Statistical analysis of data was calculated by using SPSS ver. 16 software. $P$ values of 0.05 or less were considered statistically significant. Chi-square was employed for categorical variables.

\section{Results}

Based on the interview and patients' self-report, an internalist categorized sample population into two groups; diabetic and non-diabetic ones (Table 1). The results of CIEP showed that diabetic patients were more affected to Candida albicans compared with non-diabetic individuals $(p<0.001$; Table 2$)$.

The proportion of diabetic subjects with anti-R. oryzae antibodies was higher than those of non-diabetic ones $(p<0.001$; Table 2). The relative risks were greater than one for both studied fungi, so DM was associated with both C. albicans and $R$. oryzae. However, the relative risk of candidiasis in diabetic subjects was 2.8 times more than no-diabetic subjects (Table 2 ). The relative risk of mucormycosis in diabetic subjects was 19.08 times more than no-diabetic subjects (Table 2). Absolute risk increase that has been shown as risk difference (RD) in Table 2 is 0.27 ( 2700 per 10,000 people) for candidiasis compared to 0.18 (1800 per 10,000 people) for mucormycosis. The number needed to treat (NNT) for the prevention of candidiasis and mucormycosis is 3.7 ( 370 per 10,000 people) and 5.5 (550 per 10,000 people), respectively (Table 2 ).

\section{Discussion}

In spite of an array of advanced molecular methods like

Table 1. The characteristics of selected population participated in the study.

\begin{tabular}{lcc}
\hline Group/Character & Diabetic $(\mathbf{n}=\mathbf{1 0 0})$ & Non-diabetic $(\mathbf{n}=\mathbf{1 0 0})$ \\
\hline Mean age (year) & $44 \pm 16.7$ & $38 \pm 14.2$ \\
Mean FBS (mg/dl) & $170 \pm 102$ & $90 \pm 12$ \\
\hline
\end{tabular}

FBS: Fasting blood sugar

Table 2. Outcomes of fungal infections in the diabetic and non-diabetic subjects.

\begin{tabular}{|c|c|c|c|c|c|c|}
\hline & C. albicans (+) & C. albicans (-) & Risk of C. albicans & R. oryzae $(+)$ & R. oryzae (-) & Risk of $R$. oryzae \\
\hline Diabetic $(n=100)$ & 42 & 58 & 0.42 & 19 & 81 & 0.19 \\
\hline $\begin{array}{l}\text { Non-diabetic } \\
(\mathrm{n}=100)\end{array}$ & 15 & 85 & 0.15 & 1 & 99 & 0.01 \\
\hline The relative risk & & 2.8 & & & 19.0 & \\
\hline Risk difference (RD) & & 0.27 & & & 0.18 & \\
\hline $\begin{array}{l}\text { Number needed to treat } \\
(\mathrm{NNT}=1 / \mathrm{RD})\end{array}$ & & 3.7 & & & 5.5 & \\
\hline
\end{tabular}


polymerase chain reaction and traditional microbial culture methods, qualitative and quantitative assaying of antigens of most fungal species and antibodies against them in the patient serum is nowadays the standard methodology for diagnosis of IFDs [11-14]. In this continuum, qualitative immunodiagnostic methodologies are still more economic and fast for population-based screening tests for detecting IFDs [14]. Therefore we employed CIEP in the present study to detect serum response of diabetic and non-diabetic subjects to $R$. oryzae and C. albicans.

The co-occurrence of IFDs and DM is not new story, however an efficient and economic planning to detect DM patients that are susceptible to IFDs before advancing the course of diseases would be a necessity. In the present investigation, diabetic subjects showed a more response to $R$. oryzae than healthy counterparts. In this regard, previous studies also emphasized that this opportunistic microorganism leads to some kind of lethal diseases like rhinocerebral mucormycosis in DM and other immunosuppressive conditions $[15,16]$.

High NNT (550 per 10,000 people) for $R$. oryzae affected diabetic patients in this study declares that special attention must be paid to these patients. The NNT (370 per 10,000 people) for C. albicans also showed that a good strategy must be planned to control and prevent candidiasis in diabetic patients. However lower relative risk for $C$. albicans compared with $R$. oryzae in diabetic patients represents the importance of mucormycosis vs. candidiasis in these patients. In this context, rhinocerebral mucormycosis is the most fatal fungal infection which is frequently reported in DM [17]. The most prevalent infectious cause of mucormycosis is also $R$. oryzae which belongs to the phylum of zygomycota and mucorales branches $[17,18]$.

The relative risk of candidiasis in diabetic subjects was 2.8 times more than no-diabetic subjects. Candida albicans is one of the saprophytes yeast in mucosa such as oral cavity and in the diabetic patients can cause mucocutaneous candidiasis and skin infections but cannot lead to fatal disease like rhinocerebral mucormycosis [18]. The results showed the positive serum responses against both fungi were higher among diabetic patients than healthy subjects. In addition diabetic subjects had more positive response against $C$. albicans in comparison to $R$. oryzae. In this sense, DM has been identified as an important predictor of IFDs in intensive care unit [19].

\section{Conclusions}

In sum, successful therapy for IFDs like mucormycosis and candidiasis in diabetic patients depends on early diagnosis. Hence counterimmunoelecterophoresis assay can be considered in initial screening programme, however further investigations are essential to evaluate its clinical relevance.

Competing interests

The authors declare that they have no competing interests.

Authors' contributions
\begin{tabular}{|l|c|c|}
\hline Authors' contributions & AM & IK \\
\hline Research concept and design & $\checkmark$ & -- \\
\hline Collection and/or assembly of data & $\checkmark$ & -- \\
\hline Data analysis and interpretation & -- & $\checkmark$ \\
\hline Writing the article & $\checkmark$ & $\checkmark$ \\
\hline Critical revision of the article & -- & $\checkmark$ \\
\hline Final approval of article & -- & $\checkmark$ \\
\hline Statistical analysis & -- & $\checkmark$ \\
\hline
\end{tabular}

Acknowledgement

We would like to appreciate Mrs. Nazari, Amiry, Eghbalian, Hashemian, Gobadi, Niknejad, and Mr. Karaji for their sincere assistance.

\section{Publication history}

Editor: Farzin Roohvand, Pasteur Institute of Iran, Iran.

EIC: Istiaq Quadri, King Abdul Aziz University, Jeddah, Saudi Arabia. Received: 08-Dec-2013 Final Revised: 18-Apr-2014

Accepted: 10-May-2014 Published: 21-May-2014

\section{References}

1. Rammaert B, Lanternier F, Poiree S, Kania R and Lortholary O. Diabetes and mucormycosis: a complex interplay. Diabetes Metab. 2012; 38:193204. | Article | PubMed

2. Lanternier $F$ and Lortholary $O$. Zygomycosis and diabetes mellitus. Clin Microbiol Infect. 2009; 15 Suppl 5:21-5. | Article | PubMed

3. Rodriguez MM, Serena C, Marine M, Pastor FJ and Guarro J. Posaconazole combined with amphotericin B, an effective therapy for a murine disseminated infection caused by Rhizopus oryzae. Antimicrob Agents Chemother. 2008; 52:3786-8. | Article | PubMed Abstract | PubMed Full Text

4. Demirag A, Elkhammas EA, Henry ML, Davies EA, Pelletier RP, Bumgardner GL, Dorner B and Ferguson RM. Pulmonary Rhizopus infection in a diabetic renal transplant recipient. Clin Transplant. 2000; 14:8-10. | Article | PubMed

5. Zaragoza R, Peman J, Quindos G, Iruretagoyena JR, Cuetara MS, Ramirez $\mathrm{P}$, Gomez MD, Camarena JJ, Viudes A and Ponton J. Clinical significance of the detection of Candida albicans germ tube-specific antibodies in critically ill patients. Clin Microbiol Infect. 2009; 15:592-5. | Article | PubMed

6. Goswami D, Goswami R, Banerjee U, Dadhwal V, Miglani S, Lattif AA and Kochupillai N. Pattern of Candida species isolated from patients with diabetes mellitus and vulvovaginal candidiasis and their response to single dose oral fluconazole therapy. J Infect. 2006; 52:111-7. | Article | PubMed

7. Leake JL, Dowd SE, Wolcott RD and Zischkau AM. Identification of yeast in chronic wounds using new pathogen-detection technologies. J Wound Care. 2009; 18:103-108. | Article | PubMed

8. Yeo SF and Wong B. Current status of nonculture methods for diagnosis of invasive fungal infections. Clin Microbiol Rev. 2002; 15:465-84. I Article | PubMed Abstract | PubMed Full Text

9. Mikulska M, Furfaro E and Viscoli C. Biomarkers for diagnosis and followup of invasive candidiasis: a brief review of the ECIL recommendations. Curr Fungal Infect Rep. 2012; 6:192-197. | Article

10. White PL, Parr C, Thornton C and Barnes RA. Evaluation of real-time PCR, galactomannan enzyme-linked immunosorbent assay (ELISA), and a novel lateral-flow device for diagnosis of invasive aspergillosis. $J$ Clin Microbiol. 2013; 51:1510-6. | Article | PubMed Abstract | PubMed Full $\underline{\text { Text }}$

11. Beirao F and Araujo R. State of the art diagnostic of mold diseases: a 
Mikaeili et al. Research Journal of Infectious Diseases 2014,

practical guide for clinicians. Eur J Clin Microbiol Infect Dis. 2013; 32:3-9.

| Article | PubMed

12. Baskova $L$ and Buchta $V$. Laboratory diagnostics of invasive fungal infections: an overview with emphasis on molecular approach. Folia Microbiol (Praha). 2012; 57:421-30. | Article | PubMed

13. Rogers TR, Morton CO, Springer J, Conneally E, Heinz W, Kenny C, Frost $\mathrm{S}$, Einsele $\mathrm{H}$ and Loeffler J. Combined real-time PCR and galactomannan surveillance improves diagnosis of invasive aspergillosis in high risk patients with haematological malignancies. Br J Haematol. 2013; 161:517-24. | Article | PubMed

14. Brownback KR, Pitts LR and Simpson SQ. Utility of galactomannan antigen detection in bronchoalveolar lavage fluid in immunocompromised patients. Mycoses. 2013; 56:552-8. | Article | PubMed

15. Chayakulkeeree M, Ghannoum MA and Perfect JR. Zygomycosis: the reemerging fungal infection. Eur J Clin Microbiol Infect Dis. 2006; 25:21529. | Article | PubMed

16. Kown-Chung K.J and Bennete JE. Medical mycology. 2nd ed. Lea \& Febiger. Philadelphia. 1992.

17. Abramson E, Wilson $D$ and Arky RA. Rhinocerebral phycomycosis in association with diabetic ketoacidosis. Report of two cases and a review of clinical and experimental experience with amphotericin B therapy. Ann Intern Med. 1967; 66:735-42. | Article | PubMed

18. Attapattu MC. Acute rhinocerebral mucormycosis caused by Rhizopus arrhizus from Sri Lanka. J Trop Med Hyg. 1995; 98:355-8. | PubMed

19. Liao Y, Zhong MK, Xu HB and Li L. Development and validation of a risk score for predicting invasive fungal infectious in an intensive care unit. Pharmazie. 2013; 68:459-64. | Article | PubMed

\section{Citation:}

Mikaeili A and Karimi I. The counterimmunoelectrophoretic detecting of serum response to Rhizopus oryzae and Candida albicans in diabetic and non-diabetic subjects. Res J Infect Dis. 2014; 2:2. http://dx.doi.org/10.7243/2052-5958-2-2 